\title{
Educating for the Future: A Structured Course to Train Teachers for the 21st Century
}

\author{
Eyal Weissblueth, Yonit Nissim, Shimon Amar \\ School of Education, Ohalo Academic College of Education, Sciences and Sport, Qatzrin, Israel \\ Email: eyalw@ohalo.ac.il, yonitn@ohalo.ac.il, amars@ohalo.ac.il
}

Received 16 February 2014; revised 10 March 2014; accepted 30 March 2014

Copyright (C) 2014 by authors and Scientific Research Publishing Inc.

This work is licensed under the Creative Commons Attribution International License (CC BY). http://creativecommons.org/licenses/by/4.0/

cC) (i) Open Access

\begin{abstract}
The current study relates to the construction of a course entitled "Educating for the Future" (EFTF) to equip student-teachers with high order thinking skills. The course included several stages, programs, mini projects and learning environments adapted for a "technology-assisted pedagogy" based on Intel methodology. Student-teachers learned to combine new teaching methods with information technologies while stimulating interest, thinking and creativity in their students. 454 student-teachers completed the course. Evaluation after one year showed a necessity to switch to using also other pedagogical methodologies. Second year evaluation showed that students demonstrated required behaviors and skills during their "student teaching" experience and that they change their attitudes towards adopting 21 st century skills.
\end{abstract}

\section{Keywords}

\section{1st Century Skills, Pedagogy, Learning, Adoption of Innovation}

\section{Introduction}

The entire world and especially the Western world is at present in the beginning of the digital revolution. Characteristics of the revolution include its totality and multifaceted nature (Melamed, 2010). This revolution alters man and his physical and social environment and includes technological changes in communications between different entities, institutions and human beings and in the ways in which the constantly changing knowledge and technology are handled. In general, technology advances at a much faster pace than pedagogy adopts the new technologies and it seems that the reality of the field of education still lags behind (Mishra \& Koehler, 2006). The 21st century presents a multi-faceted reality and embodies many trends; it is characterized by globa- 
lization, rapid technological development, dynamism and significant, widespread socio-economic processes. Current reviews, conducted by the Center for Educational Technology (2010) indicate that the younger generation is now exposed to intense changes, far more than in the past. Routine knowledge will not prepare young people for life in the 21st century. Thus, innovation and creativity, team work and collaboration must be central components in learning programs". In other words, a "new pedagogy" is needed.

Frequent socio-economic changes and new global trends clearly indicate that a new and broader perception is needed to bridge gaps in education and learning that result from this dynamic upheaval. Students must be educated within the education system to become the citizens of tomorrow in order to cope with the challenges of the information era. At the same time the training process for student-teachers must prepare them to be the teachers of tomorrow, since they themselves also suffer from these gaps.

Despite the level of willingness of the student-teachers to integrate technology in their pedagogy, the existing infrastructure in most school classes in Israel, especially the peripheral regions, does not permit this. Additionally, according to Givon (2004) there is a lack of an appropriate method ("the missing link") that would empower teachers to use technology intelligently and correctly for teaching purposes. Nachmias et al. (2004) suggested that teaching higher order skills would facilitate the use of advanced technology by teachers and indicated that this should be a central goal for education (The Partnership for 21st century skills, 2003, 2010).

In addition to these goals, it is important to develop the students' abilities to become active and involved learners with motivation for learning. Many students are very involved in the new technologies, so that they participate with greater ease in the teaching process. This means that the teachers can set the students' problems and situations with which they are not familiar with the assistance of technology in order to promote problem-solving, encourage and provide possibilities for the asking of questions, foster evaluative thinking and promote the students' abilities for decision-making as they solve problems. This will contribute to a change in perceptions, values and education (Center for Educational Technology, 2010). However, as they introduce communications technology in their teaching, in their internship practice, and in their first year as novice teachers, studentteachers already encounter many difficulties such as: a gap between theory and the reality in the field that influences and creates different pressures such as: time pressure, disciplinary problems etc. (Segal-Drori et al., 2009). Therefore, the relevant knowledge that needs to be taken into account when training teachers is content-pedagogic-technological knowledge (Mishra \& Koehler, 2006). An inter-generational gap is created due to the gap in knowledge from the time when the teacher was a student to the time when they have to be the person who bears the educational messages to the next generation.

Ohalo Academic College has identified the immediate need for an alteration of paradigms and recognition of these gaps. This has led to the formation of the "EFTF" course that was prepared with the cooperation of Intel World Company as a pioneer attempt to provide an appropriate holistic response to bridge the gaps, in accordance with the needs that the many technological changes create within the teaching field. The course aims were: 1) To respond to the need for an innovative combination of tomorrow's pedagogy employing modern technology as a facilitating element for teaching; 2) To create a significant change in the teaching, learning and evaluation processes assisted by technological systems and computerization in order to implement different pedagogical aspects in the classroom; 3) To bridge the gaps between tomorrow's teachers and their students; 4) To create interesting learning and to develop skills and abilities suitable for the 21st century. This called for a change in learning programs, materials, organization, lesson curricula, teaching tools and resources in order to transform the school so that it can prepare its students for the knowledge society and for a dynamic world that does not acknowledge the limitations of time and place (Mioduser et al., 2006). The course's central focus related to the development of different thinking principles aided by technological means to enable teachers and students to think "outside the box". The course was composed of several stages that provided student-teachers with different tools, some the products developed by Intel company, to enable them to instruct, guide, alter, teach, challenge and educate their students in an atmosphere relevant to their own present-day world. The different tools and platforms were introduced as an integral part of the different learning units and lesson plans that the student-teachers constructed for their students.

Among the tools in the broad toolbox provided to the student-teachers during the years of their teacher training, they are exposed to several platforms, learning and thinking tools, digital tools, presentations, films and film clips, animation programs, Internet sites, use of the smart phones and digital cameras, video and stills, games and activities (without technological means) that illustrate and emphasize cooperation and team work, planning tools, Google docs etc. These tools were used as facilitating aids to serve a new pedagogy, enabling student- 
teachers to acquire and develop skills such as: identification, sorting, selection, labeling, creation of analysis and synthesis, development of creativity, team work, and collaboration through different technological means. The main theoretical foundation for these skills is Blum's taxonomy, which indicates that the student needs new thinking skills and high order thinking to be able to produce the expected products within the modern learning process.

The "EFTF" course constituted a first step in the training of student-teachers' studies in the college and provided the "missing link" to bridge the gap of knowledge between teachers training in the schools and the students that study there who have grown up with present day technological developments. The program was designed to teach the student-teacher, from the first day of their training, to use pedagogic-didactic tools that make effective use of existing technology. During their training at the college the student teacher is exposed to advanced teaching methods and practices these methods, delivering presentations to an audience of learners on several occasions. They train to create teaching practices adapted to the 21st century, to become comfortable with the use of Internet thinking tools and the participatory technologies involved and to construct processes for the assimilation of change in teaching and learning practices such as: teaching through the development of creative thinking methods, data-storage through technological means (in contrast to relying on the human mind), comprehension of what was learned in a more profound manner, development of exercising skills, and the use of unique technological tools. All this was integrated within the student-teachers' administration of their computerized interactions with the learners, while the student-teachers' were guided through computerized interaction with their lecturers, preparing the student-teacher so that immediately after graduation and their entry into the education system they would be better equipped and ready for their mission. The "EFTF" course constitutes a central part of these processes: 1) Establishment of a center for technology-rich knowledge, learning and teaching that will expand the college's pedagogic center and unite it with the library; 2) Construction of a computerized interface between the college, its services and knowledge with the lecturers and students (portal); 3) The "EFTF" course-empowerment of the college's lecturers and students with the use of advanced technologies found at the forefront of modern educational activities. This includes the promotion of sophisticated strategies that the Ministry of Education is interested in introducing to the education system (Rimon, 2010) since they encourage creative thinking and impart the necessary skills for the digital era such as: cooperation, collaboration, searching for relevant information and evaluating the data etc. After two years of its operation, we started to evaluate the changes made in the course and how well it adheres to its objectives.

\section{Methodology}

This was an action research in which the researchers were involved both as researchers and as lecturers. Because of the unique and complex nature of the studied subject a multi-layered qualitative and quantitative data-collection and analysis approach was adopted. In our opinion, this mixed methods approach is appropriate for the analysis of the novel technology-assisted pedagogy, constructed as part of a broader perception that change in teacher training is essential to prepare student teachers for tomorrow's reality. Conclusions and insights emerging from the implementation of the "EFTF" course until now will be used to improve the course in the future. In order to achieve this aim we triangulated the analyzed data from the questionnaires and assessment feedback with the data from interviews with student focus groups and documentation relating to the lecturers' staff meetings. This process validated and reinforced the research data.

\subsection{Research Goals and Questions}

To present a unique case study that would analyze the creation and implementation of a new pedagogy teaching 21st century skills in the Ohalo academic teacher-education college. We were interested to know if the goals of the "EFTF" course and its rationale met the needs of student-teachers in 1st, 2nd, 3rd and 4th years. Which content and activities are planned for the course and do they comply with the college's needs and goals? Are the course's goals, and planned contents and activities suitable for its implementation? If so- to what extent? If not - why not? And how did students accept the innovative course? Was their assimilation of the course content easy or difficult? Were there identifiable differences in the reactions of student-teachers in different disciplines?

\subsection{Research Population and Tools}

The research population consisted of 561 college students in all four year courses. 454 students in 2011 and 107 
students in 2012, majoring in the following academic disciplines: Kindergarten teaching, Physical Education, Science teaching and general Elementary teaching in several minors: English, Special Education and Mathematics. Research tools were chosen and adapted to meet the task of evaluating the project after two years operation. Approval of the college's IRB was obtained and the following measuring and evaluation tools were used to collect data concerning the effect of the program at the end of the first and again at the end of the second year of the course's operation: 1) Project documents, 2) Interviews with role holders, 3) TAO questionnaire, 4) Evaluation questionnaire for course and lecturer, 5) Focus groups from each year. Interviews were held with four focus groups consisting of representative volunteering students from each of the four years classes. Interviews were conducted after the end of the first course. 24 participants took part in the focus groups (6 from each year group and each learning disciplines). Interviews were recorded and transcribed. Face validity of questionnaires and other research tools was tested by three experts from the course's lecturer staff. Students' feedback questionnaires were standard tools regularly used as a means of assessing teaching quality in all the college's courses. Using qualitative content analysis, we divided the interview transcripts into units of meaning according to their content. This analysis yielded several central conclusions that can be considered as the achievements of the course also pointing at the difficulties and deliberations with which the student-teachers had to cope. The analysis also shed additional light on several theoretical issues.

\section{Results}

\subsection{Evaluation-Year 1, 2011}

The following are the analyzed data from the TAO questionnaire that underwent "face validation" by three experts from the lecturer staff of the course. The evaluation relied on closed-ended questions and on open remarks. 73 student-teachers out of $1321^{\text {st }}$ year students completed the TAO questionnaires (55\%) at the end of the course. 59 students chose not to participate. Of those 132 students 97 were designated to fill the course evaluation questionnaire and 47 actually did and the rest chose not to fill the course evaluation questionnaire. Questionnaires were completed voluntarily. The quantitative data underwent statistical processing. Detailed results for the first year of the course are presented below in Table 1.

Study of the data revealed that there was partial satisfaction regarding the course. Nevertheless approximately half the student-teachers (56\%\# 1, 2, 3 in Table 1) noted that they would use the thinking skills that they learned in the course while 30\% (\# 5 in Table 1) answered that they would not use the skills in the future and 14\% (\# 4 and 6 in Table 1) noted that they did not yet know if they would use them. These results are not surprising, since they are in line with previous studies that found that "pre-service teachers and practicing teachers continue to reveal difficulties in relation to information technologies and their integration in teaching, many of them lack a structured strategy to integrate them in the learning program” (Oliver, 1994). Other student teachers reveal anxiety and fear of using these skills in practice due to lack of experience and resistance. In order to reduce resistance teachers should be given relevant training. Knowledge reduces resistance and uncertainty and practice facilitates the assimilation of changes (Abu Ahmed, 2010).

A most positive sign was seen in the responses when the student-teachers were asked to choose a sentence

Table 1. Distribution of responses to the evaluation questionnaire in the "EFTF" course 2011.

\begin{tabular}{|c|c|c|c|}
\hline No. & Response & $\mathrm{n}$ & $\%$ \\
\hline 1 & $\begin{array}{l}\text { I can envisage using one or more of the applications/learning channels that I have learnt in the } \\
\text { workshop in the future in my class. }\end{array}$ & 24 & $32.88 \%$ \\
\hline 2 & $\begin{array}{l}\text { I am thinking about a particular lesson that will include what I have studied and I intend to perform } \\
\text { this lesson in the coming weeks/months. }\end{array}$ & 9 & $12.33 \%$ \\
\hline 3 & $\begin{array}{l}\text { I have some sort of general conception how I will use what I have learnt in the workshop but I have } \\
\text { no specific lesson in mind yet. }\end{array}$ & 8 & $10.96 \%$ \\
\hline 4 & $\begin{array}{l}\text { I have some general conception of how I will use the tool(s) at some time this year, but I am not sure } \\
\text { when or how. }\end{array}$ & 6 & $8.22 \%$ \\
\hline 5 & It seems that I will not use the studied platform during this year. & 22 & $30.14 \%$ \\
\hline 6 & Due to my present learning program and time limitations, it seems that I will not use the studied platform. & 4 & $5.48 \%$ \\
\hline 7 & I will use the platform solely to help me with peer learning and collaboration on the net. & 0 & $0.00 \%$ \\
\hline
\end{tabular}


that best represented their plans to use the thinking tools for teaching their students in class; most of them (64\%) responded that they would use the thinking tools in some manner although the remaining students (36\%) responded that they would not use the tools that they had learned.

The data from the feedback presented above was reinforced by some of the data from the structured interviews with the focus groups. They were asked if this course altered or influenced their first thought of teaching style in any way. They responded that they "...simply perform a computerized lesson for them now" or "It influenced me" and "I will now determine points before each lesson. I take several important, major points that I write down on the side, on the text or even on the board and I actually consider them, although all the time I focus on the students there, I lead the students to those points, I utilize my lesson unit, I exploit it to the end only for matters that are relevant to what I want to transmit.

With regard to the question: to what extent did the course help you on the professional level, $69 \%$ answered that it helped to a medium and lesser extent while $31 \%$ answered that it helped them to a large or very large extent, see Table 2.

Verbal responses in the interviews and responses to open-ended questions which were not analyzed quantitatively underwent content analysis and were divided into several categories of meaningful units and graded according to quantitative amount, counting the number of associated responses for each category to which we assigned the relevant statements. Statements were recorded and transcribed, maintaining the original language without any rewriting or editing, in order to retain the student-teachers' authentic expressions, representing their feelings and their voice in a trustworthy manner. The emergent categories and representative statements included "Uncomfortable computer tools and software", "Low level of college computer system and infrastructure", "Not attractive course methods", "Wrong timing of the course in the training process of becoming a teacher", "Unsuitability for those training for early childhood and kindergarten teaching", "Poor quality of course lecturers".

A significant question emerged from the students' remarks in class and data from the feedback and the open remarks: is it possible to adapt the "EFTF" course so that it will also be suitable for those training to become kindergarten and physical education teachers? The answer to this question is complex and involves a matter that was emphasized in the focus group interviews. We discovered that there was more complexity and difficulty in the implementation, understanding and internalization of the necessary pedagogic change in these two disciplines, both from the teaching aspect and from the learning aspect: 1) Students and lecturers in the course found it difficult to explain, and to vision the manner in which the integration and use of technology could be applied to the early children and physical education professions; 2) The problem, of lack of computers in kindergartens was often cited, as impeding and even preventing the adoption of the innovative computer-assisted pedagogy; 3) Conservative "traditional" views adhered to "old pedagogy" that did not allow the adoption of an innovative approach in the disciplinary areas of education for early childhood.

Analysis of the questionnaire data and the data from the focus group yielded several main themes. In line with the theory arguing that due to a lack of experience, teachers will resist change, the content analysis of the qualitative data indicated that students experienced anxiety and fears. This led to resistance. To reduce resistance teachers should be trained (Sarason, 1993) since knowledge reduces resistance. It was therefore decided to continue the course but to analyze the findings, drawing conclusions that would form the basis for changes and improvements in both the pedagogic aspect (making the program more appropriate for the types of trainees and different needs), and also in the technological aspect (the use of different tools and software). The respondents' remarks indicated that the sense of satisfaction regarding the course was only partial. Consequently a significant

Table 2. Distribution of responses to the focus group question:

"To what extent did the course help you on the professional level?”

\begin{tabular}{ccc}
\hline Response & $\mathrm{n}$ & $\%$ \\
\hline To a very small extent & 15 & $20.55 \%$ \\
To a small extent & 11 & $15.07 \%$ \\
To a medium extent & 24 & $32.88 \%$ \\
To a large extent & 16 & $21.92 \%$ \\
To a very large extent & 7 & $9.59 \%$ \\
\hline
\end{tabular}


change process was conducted that included: enhancement of the computer infrastructure, alteration of course contents, replacement of lecturers who it were considered significantly unsatisfactory, alteration of the computerized teaching method, addition of independent—creative dimensions of work and presentation of the students products, with more user-friendly tools (Scratch, animations, time axis etc.). These conclusions and insights were implemented in the "EFTF" course in 2012. Changes were made in the course contents, lecturers adapted to these contents and new more challenging tools were introduced. Additionally the physical infrastructure of the information systems and college computers was improved and underwent changes. The main changes made in course content from 2011 to 2012 are summarized in Table 3.

\subsection{Evaluation-Year 2, 2012}

After all these alterations were implemented, evaluative feedback was collected at the end of the second year to re-examine teaching and learning aspects of the course. 107 1st year students took the EFTF course. The evaluation relied on similar closed-ended questions as in 2011 and on remarks in response to open-ended questions. 31 student-teachers out of 44 completed the TAO questionnaire (70\%) at the end of the course. The questionnaire was completed voluntarily. Also, 56 out of 107 designated students answered course evaluation questionnaire. The quantitative data underwent statistical processing.

We analyzed student's feedback in the Evaluation questionnaire at the end of the second year in 2012. The analysis indicated that there was a significant improvement in many of the investigated dimensions. An independent-samples t-test was conducted to compare student' responses for each item in 2011 with respective responses in 2012.

As seen in Figure 1 there was a significant difference between the scores for students' self-grading in 2011 $(\mathrm{M}=3.9, \mathrm{~V}=0.02)$ and in $2012(\mathrm{M}=4.3, \mathrm{~V}=0.03) ; \mathrm{t}(7)=-4.2, p<0.01$. These results suggest that students graded themselves higher in 2012 compared with 2011. Specifically, our results suggest that students felt they learned and performed better in 2012 than those in 2011.

There was a significant difference in the scores for student' perception of their investment in the course in $2011(\mathrm{M}=3.69, \mathrm{~V}=0.04)$ and in $2012(\mathrm{M}=4.5, \mathrm{~V}=0.04)$; $\mathrm{t}(7)=-5.5, p<0.001$. These results suggest that students perceived their efforts to be higher in 2012 compared with 2011. Specifically, our results suggest that students felt they worked harder in the course of 2012 than in that of 2011.

Also emerging from the analysis is that there was a significant difference in the scores for student' perception of how hard they had to work in the course or how difficult the course was in $2011(\mathrm{M}=2.35, \mathrm{~V}=0.24)$ and in $2012(\mathrm{M}=3.41, \mathrm{~V}=0.15) ; \mathrm{t}(6)=-2.7, p=0.01$. These results suggest that students perceived the course to be harder in 2012 than in 2011. Specifically, our results suggest that students felt that the course was harder in 2012 than in 2011.

The analysis shows that there was a significant difference in the scores for student's total course evaluation. It was lower in $2011(\mathrm{M}=3.54, \mathrm{~V}=0.19)$ than in $2012(\mathrm{M}=4.34, \mathrm{~V}=0.05)$; $\mathrm{t}(4)=-3.2, p=0.01$. These results suggest that students evaluated the course as better in 2012 than in 2011. Meaning, our results suggest that students felt that the course was better in 2012 than in 2011.

Table 3. Main changes made in course content from 2011 to 2012.

\begin{tabular}{lcc}
\hline The category & 2011 \\
\hline Thinking skills (HOTS and 21st century skills) & $\sqrt{ }$ \\
Learning taxonomies & $\sqrt{ }$ & $\sqrt{ }$ \\
Intel's computerized thinking tools & $\sqrt{ }$ \\
Development of computer-assisted learning units & $\sqrt{ }$ \\
Evaluation and assessment in learning & $\sqrt{ }$ \\
The “Teachers Advanced Online” platform & $\sqrt{ }$ \\
The “Elements” program & $\sqrt{ }$ \\
Computer \& Internet skills: Google+, Google docs, and social networks & $\sqrt{ }$ \\
Computerized motifs: time lines, digital stories, Scratch, digital animations & $\sqrt{ }$ \\
Integration of presentation, digital photography & $\sqrt{ }$ \\
\hline
\end{tabular}




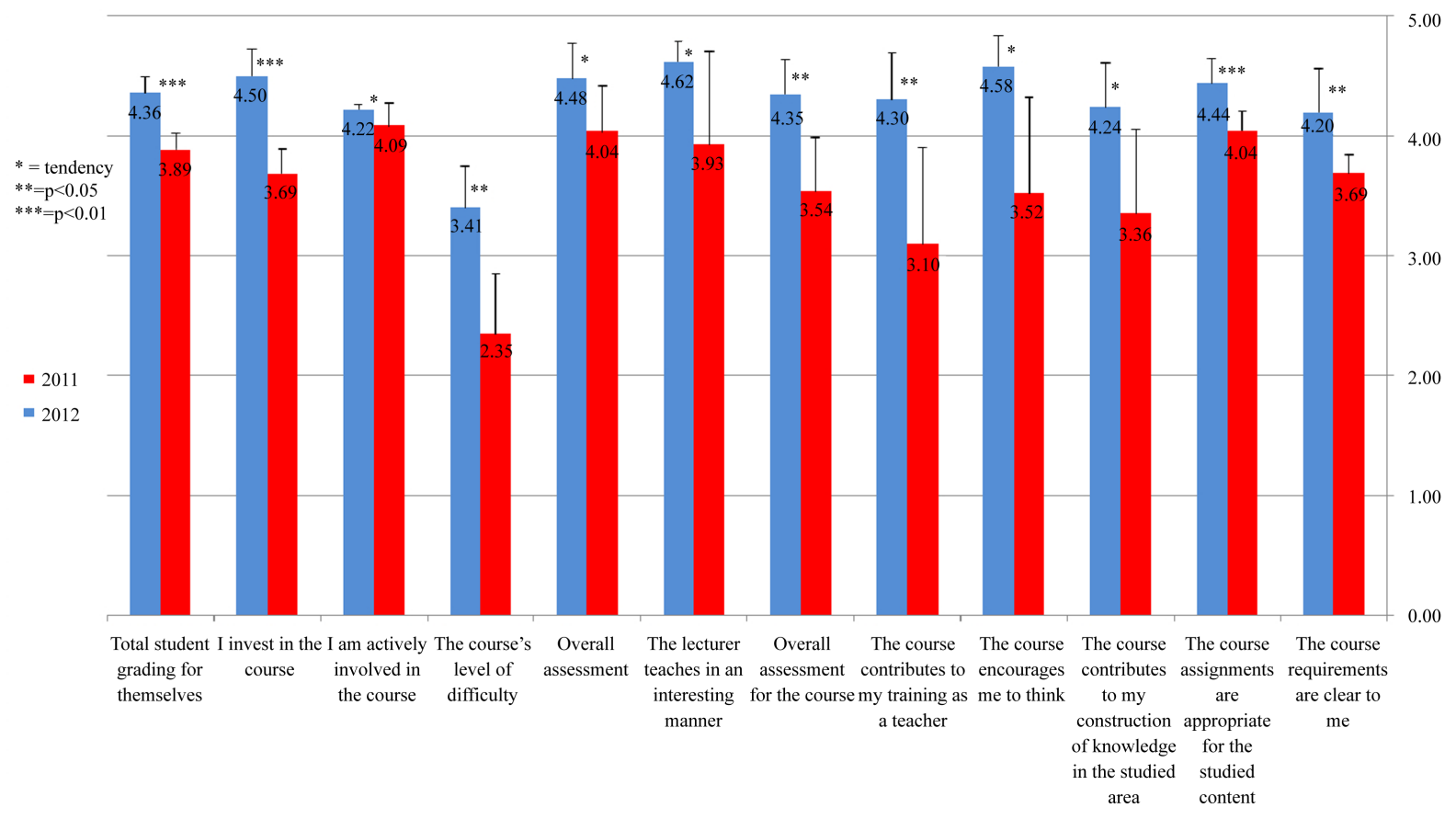

Figure 1. Comparative content analysis for feedback between years 2011 and 2012 by statement (mean scores on a scale of 1 - 5, 5 = strong agreement).

Concerning how the course contributed to the students, the analysis shows that there was a significant difference in the scores between $2011(\mathrm{M}=3.1, \mathrm{~V}=0.6)$ and $2012(\mathrm{M}=4.3, \mathrm{~V}=0.07) ; \mathrm{t}(4)=-2.8, p<0.05$. These results suggest that students felt the course contributed more to their training in 2012 than in 2011. Specifically, our results suggest that students felt that the course was more beneficial to them in 2012 than in 2011.

Figure 1 also shows two main findings concerning the extent of clarity of course assignments and the extent of clarity of course requirements. Both were graded significantly lower in $2011(\mathrm{M}=4.04$ and $\mathrm{V}=0.02 ; \mathrm{M}=$ $3.69, \mathrm{~V}=0.02$ respectively) and higher in $2012(\mathrm{M}=4.44$ and $\mathrm{V}=0.04 ; \mathrm{M}=4.2, \mathrm{~V}=0.13$ respectively). These results suggest that course assignments and requirements were clearer to the students in 2012 than in 2011.

Table 4 presents a comparison of qualitative data comparing the results of the content analysis of remarks provided in response to open-ended questions in questionnaires between the years 2011 and 2012. Additional reinforcement for these conclusions is found in the lecturers' "voices", since these units of meaning also emerged from the content analysis of discussion of different issues in staff meetings and relates to the conclusions and insights that appeared there and were reported in the protocols; they were also mentioned in interviews with main role holders in the course, as additional reflection on the process, for example in the Protocol from Staff Meeting 4.

Even among the course lecturers there was difficulty with regard to the relevance of the course contents and the way in which they could be implemented for early childhood. Therefore it was decided that the lecturers who were teaching in the early childhood streams would develop an alternative program that was more suitable to this specific training, which would include an emphasis on creativity and the use of available technology adapted for those studying in this area, taking into consideration the limitation of lack of reading and writing skills in early childhood.

One of the conclusions from the lecturers' meetings was that the lecturers who were awarded the best feedback for all categories should be chosen for the second year of the course. The lecturers agreed that the goals were achieved despite the high level of technical difficulties. It appeared that it was possible to provide creative alternative learning even when the technology was defective.

In order to gain an impression of the success of the course and the extent to which the main concept of fostering teaching abilities among student teachers for 21st century skills had been implemented in their classrooms, we decided to present a learning unit with 3 lessons including the use of different technological tools and methods. 
Table 4. Comparison of qualitative data for the years 2011 and 2012.

\begin{tabular}{|c|c|c|}
\hline The category & Remarks 2011 & Remarks 2012 \\
\hline Tools & $\begin{array}{l}\text { "I'm not clear how these tools are relevant for me"; } \\
\text { "I'm not sure how I can use this tool". }\end{array}$ & $\begin{array}{l}\text { "There is practical use of the tool for the lesson syllabus } \\
\text { that we use in our practical experience" }\end{array}$ \\
\hline \multicolumn{3}{|c|}{$\begin{array}{l}\text { Computer systems and "The computers in this room are old, most of them d } \\
\text { infrastructure in the not function properly". } \\
\text { college }\end{array}$} \\
\hline Course methods & $\begin{array}{l}\text { "More homogeneous groups"; "to alter the content"; } \\
\text { "to try to transmit the lesson practically"; "to prepare it } \\
\text { in a manner that will teach us in more depth about } \\
\text { teaching and thinking”; "the exercises delivered in class } \\
\text { are unclear to me”. }\end{array}$ & $\begin{array}{l}\text { “A good course”; "the lesson procedure was very good, } \\
\text { should not be changed”; “the course was experiential, } \\
\text { interesting and contributes much”; “an interesting course, } \\
\text { develops thinking”; “students’ presentations contribute to } \\
\text { general knowledge and the feedback makes the learning } \\
\text { more practical”. }\end{array}$ \\
\hline $\begin{array}{l}\text { Timing of the course in } \\
\text { the training process }\end{array}$ & $\begin{array}{l}\text { "To refresh the course requirements and its purpose for } \\
\text { me"; "I'm not sure what the course contributes to my } \\
\text { future as a teacher". }\end{array}$ & $\begin{array}{l}\text { "The course was suitable for the stage where we were, so } \\
\text { that it was important to take it". }\end{array}$ \\
\hline $\begin{array}{l}\text { Suitability for early } \\
\text { childhood trainees }\end{array}$ & $\begin{array}{l}\text { "The course should have a stronger connection with the } \\
\text { discipline. I'm unclear how this course connects to my } \\
\text { stream"; "I'm not sure what the course's goal is". }\end{array}$ & $\begin{array}{l}\text { "It should be clearer how it will help me in the future as a } \\
\text { teacher"; "in my opinion the course does not contribute to } \\
\text { my training as a kindergarten teacher". }\end{array}$ \\
\hline Lecturer quality & $\begin{array}{l}\text { "I feel that the content itself is really stretched out and } \\
\text { continues without reason in order to fill the lesson, not } \\
\text { only with this lecturer". }\end{array}$ & $\begin{array}{l}\text { "Its advisable to keep the lecturer"; "the lecturer is very } \\
\text { professional"; "the lecturer was fascinating and good"; } \\
\text { "the teacher was excellent ,we learnt a lot from her"; "he } \\
\text { makes us think outside the box". }\end{array}$ \\
\hline Miscellaneous & $\begin{array}{l}\text { "It should become a one-semester course”; “it’s a } \\
\text { superfluous course"; "the course could be concentrated } \\
\text { in two lessons". }\end{array}$ & \\
\hline
\end{tabular}

The lecturers in this field expressed satisfaction regarding the quality of the learning units. One example can be seen in the protocol of Staff Meeting 7: A learning unit entitled "Sexual harassment" was presented by the lecturer, RA. This was a complete learning unit constructed according to the course directive, testifying that the course goal had been achieved. The lecturers' indicated that most of the student-teachers prepared their learning units in the spirit of the "EFTF" course. They concluded that the quality of the learning units produced at the end of the course indicated that the goal of creating educators for the world of tomorrow was being achieved and that the course contents were compatible with the course goals. Nevertheless, they felt there was room to improve the learning tools to include more advanced and creative learning tools: "the course is appropriate but the thinking tools of Intel are primitive and inflexible so that they do not serve the course goals". When these tools broke down it created a sort of "own goal" because as one lecturer claimed "the students in Year 1 don't have sufficient training and background in basic computer software (Office), the pedagogic mentor needs to study the course and also it is important not to give the course in the afternoon due to fatigue" (2011). These findings tallied with the students' remarks found in the content analysis presented earlier.

\subsection{Adoption of Educational Innovation}

We used points of midrange to examine different categories of the student-teachers' adaptation including changes in attitudes toward adopting knowledge concerning newer teaching methods.

From Figure 2 it is visually evident (points of midrange of 2011 and 2012 were $14.4 \%$ and $27.6 \%$ respectively) that more students adopted knowledge on new teaching methods in 2012 than in 2011.

Points of midrange were also used to examine changes in the student-teachers' feelings regarding the acquisition of tools to improve their teaching, learning and evaluation. It is visually evident in Figure 3 (points of midrange of 2011 and 2012 were $18.5 \%$ and $19.5 \%$ respectively) that more students feel they acquired tools to improve their teaching, learning and evaluation in 2012 than in 2011.

This was also the case with regard to the student-teachers' feelings that they had "developed thinking skills". in the data in Figure 4 shows that more students felt they acquired knowledge in regard to "developing thinking skills" in 2012 than in 2011 (points of midrange of 2011 and 2012 were $18.5 \%$ and 24.2\% respectively).

With regard to the students' feelings concerning their level of "cooperation with other teachers", Figure 5 shows that more students felt they acquired knowledge in "developing thinking skills" or cooperation with other teachers in 2012 than in 2011 (points of midrange of 2011 and 2012 were 16.4\% and 20.7\% respectively). 


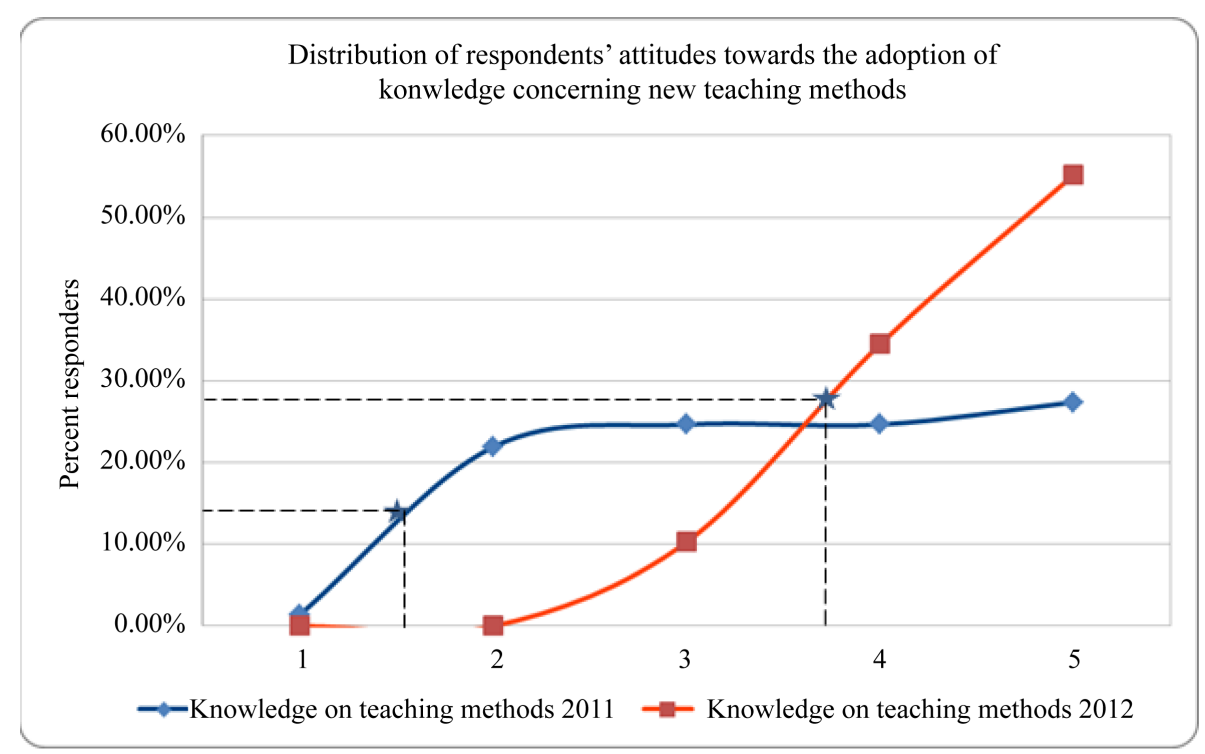

Figure 2. Categories of adaptation: Adoption of knowledge on teaching methods (mean scores of agreement on a scale of $1-5,1=$ Not at all, $2=$ A little bit, $3=$ Reasonably, $4=$ Very much, 5 = Fully agree).

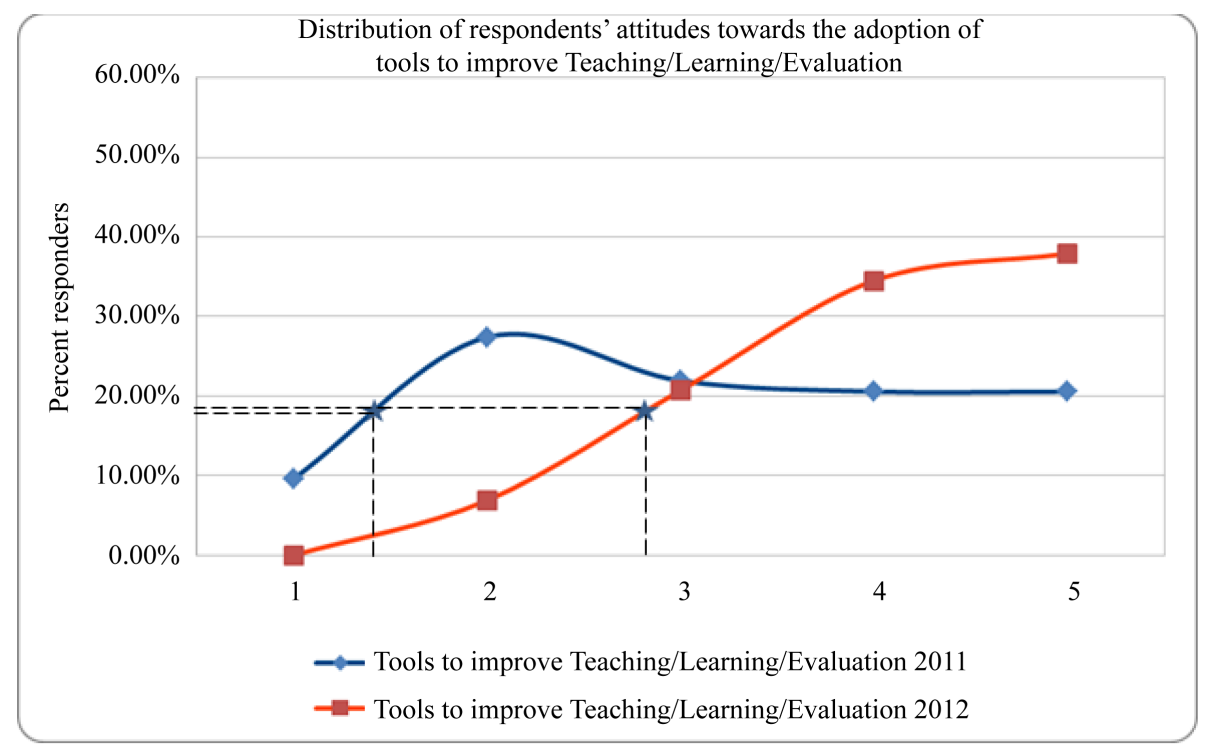

Figure 3. Categories of adaptation: Adoption of tools to improve teaching/learning/evaluation (mean scores of agreement on a scale of $1-5,1=$ Not at all, $2=$ A little bit, $3=$ Reasonably, 4 = Very much, 5 = Fully agree).

\section{Discussion, Conclusions, Recommendations and Plans for the Future}

Many studies have dealt with the connection between the development of information technology and the shaping of new pedagogy. Most of them tend to search for the "missing link" that could integrate the use of technology within an "alternative" pedagogy adapted to the needs of the 21st century. Other studies point up the influence of technology on teachers' teaching processes (Mioduser et al., 2006). They suggest a broadening of the learning environment beyond the well-known familiar classroom space that has been used for more than 100 years. The "EFTF" course that began in October 2010 aimed to provide a response to these needs, to begin to train the teachers of the future, student-teachers, from the first stages of their training to use "alternative" and "innovative" teaching methods, pedagogy and didactics adapted for the development of 21st century skills. 


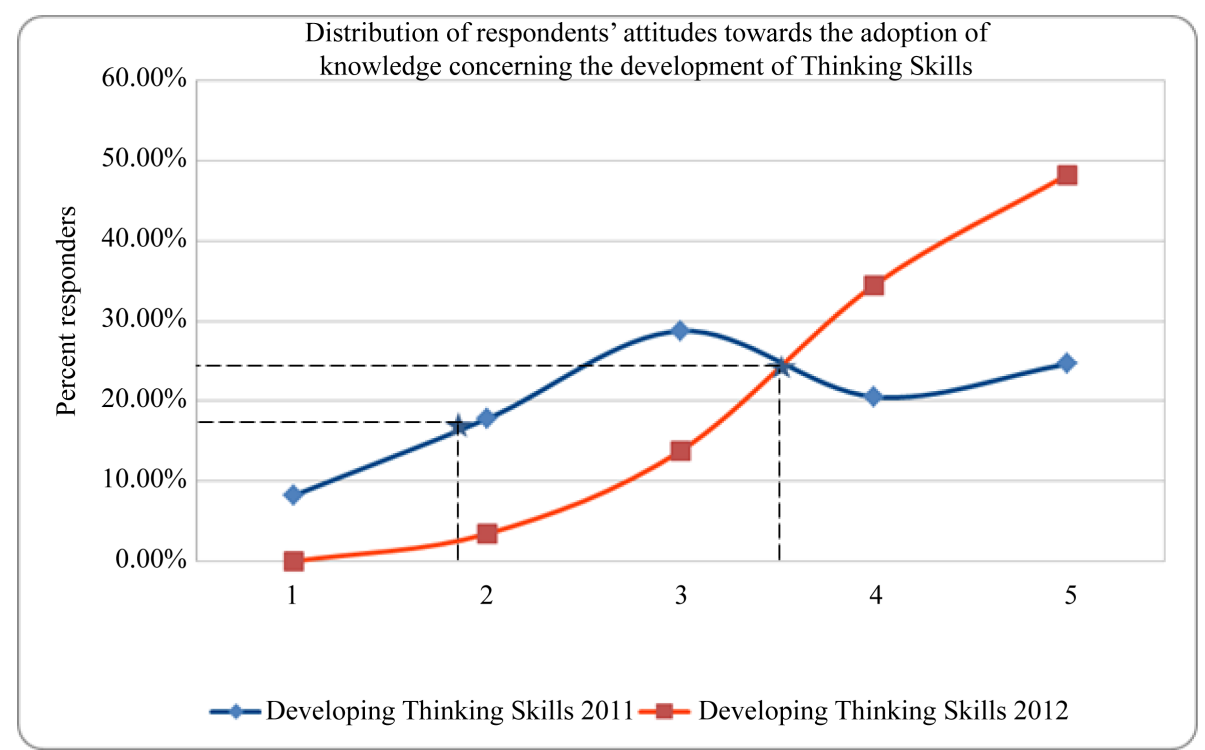

Figure 4. Categories of adaptation: Adoption of developing thinking Skills (mean scores of agreement on a scale of $1-5,1=$ Not at all, $2=$ A little bit, $3=$ Reasonably, $4=$ Very much, 5 = Fully agree).

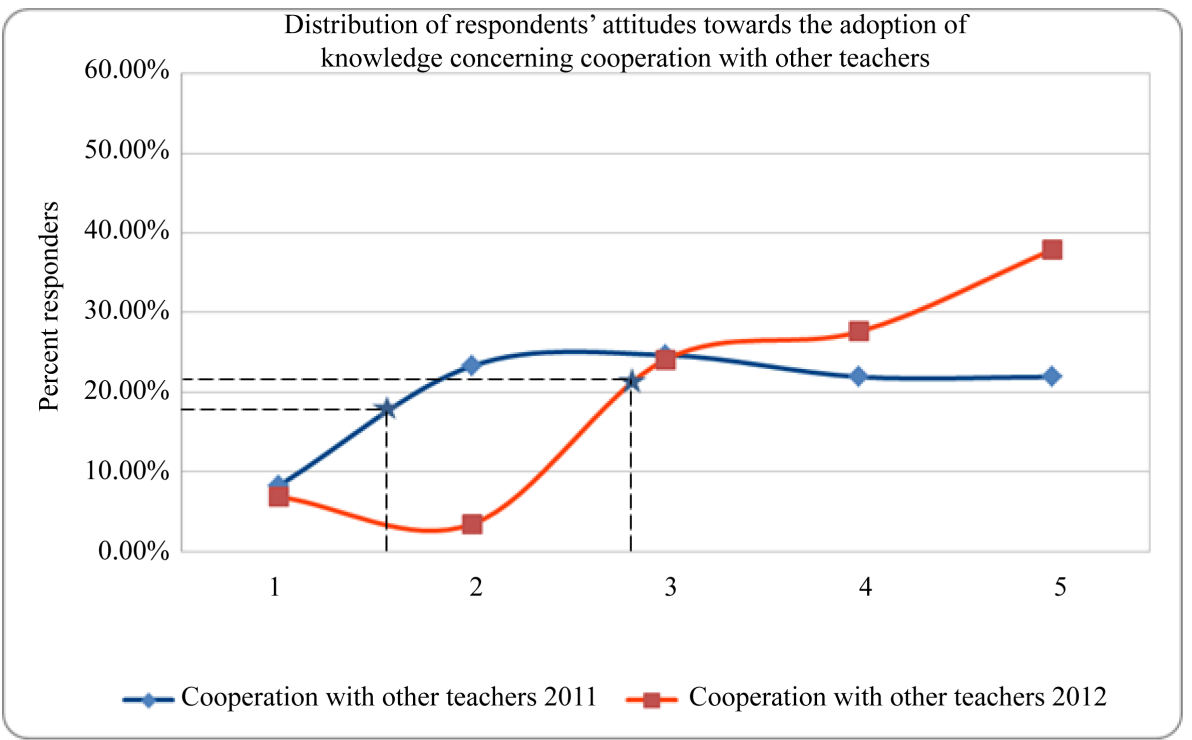

Figure 5. Categories of adaptation: Adoption of Cooperation with other teachers (mean scores of agreement on a scale of $1-5,1=$ Not at all, $2=$ A little bit, $3=$ Reasonably, $4=$ Very much, 5 = Fully agree).

The first stage in the implementation of this program was accompanied by many difficulties, both on the part of the lecturers teaching the program and on the part of the student-teachers. Achievements were attained by the creation and introduction of a change in perceptions of a "conservative" and traditional profession (relating to the character of the student-teacher population and the image of the teaching profession as one which has not undergone substantial changes for many generations).

Any change and innovation encounters resistance to a certain extent. However, after the first year of the new course, in line with the results of evaluation processes that indicated partial satisfaction with the course and indepth thinking, improvements and alterations were introduced into the second year performance of the course. From the analysis of findings from the different evaluation tools, it seems valid to assert with some certainty that 
the lessons were learned, and that the improvements that were implemented led to learning and teaching at a very satisfactory level. Moreover, it is obvious that at the end of the second year the innovative messages began to be accepted among the student-teachers and also among the lecturer staff of the course.

There was a difference between the different year groups in their consideration of the course and with regard to the timing of the course. Students in Year 1 had difficulty at first in accepting the perceptions, the subject and the manner and method of learning. It was clear that these difficulties stemmed from the timing of the course at the very beginning of their studies. This explanation is supported by evidence indicating qualitative differences in experiences at specific points of the student-teacher's development, as a future teacher progressing on the time axis of professional development. The situation is made more complex by the fact that "teachers like students have unique learning styles and unique needs for problem-solving" (Sergiovanni, 2002). Thus, there were significant differences in the way in which different individuals perceived the course in their personal experience. In our opinion, this is a product of the students' individual perceptions and beliefs concerning the teaching and education profession; perceptions that may be influenced to a greater or lesser degree by the traditional approach to education within which they were educated in their childhood.

There were gaps between the stated goals and the manner in which the lecturers understood the course's rationale and the manner in which contents and the training were delivered and the students' understanding. In other words, in the first year there was a gap between the reality (understanding and assimilation of EFTF messages) and the ideal (rationale and vision). This gap might stem from the innovative nature of the tools, and the EFTF message, and technical difficulties of different types.

To summarize the main findings: There were gaps between reality and the ideal, between the desire to implement the innovative pedagogy and the level of computerization in the education field. The level of computerization in the classrooms and especially in the kindergartens has not yet reached the stage where it is possible to conduct computer-assisted digital lessons in the spirit of the "EFTF" course. In the best scenario there is one old and outdated computer with software that is not connected to the Internet. Once a week upon arrival to school for their practical internship, student-teachers who were trained in the EFTF course encounter, a standard classroom that has not altered significantly in the last hundred years. This dissonance creates a complexity that the students pointed up during the interviews and in their feedback and conversations during lessons.

All the above-mentioned points indicate that there are individual differences and perceptions among students and lecturers. The "EFTF" course involves a change in perception and offers an innovative pedagogy; however each lecturer and each student-teacher brings their own individual understandings into the classroom, so that we found many differences between the respondents' opinions in relation to each of the dominant categories that emerged from the data analysis. The differences might stem from their personal perceptions of education, learning, teaching and "either consciously or sub-consciously the teachers' perceptions have a decisive influence on their work methods in the classroom" (Albion, 2003; Ertmer, 2005; Lim \& Khine, 2006; Park \& Ertmer, 2008; Scrimshaw, 2004, all cited in Wadmany \& Levin, 2004). The individual's perceptions or world views probably are a significant component in the teacher's decision concerning which methods and approaches to adopt in their teaching work and in their willingness to adopt novel teaching environments, processes and goals. Additionally educational reform cannot occur without adaptation of the teacher's pedagogic approach (Ertman et al., 2006 in Levin \& Wadmany, 2008).

Although lessons were learnt after the first year of the course and alterations were made to the course in the second year, it is still too early to derive far-reaching conclusions at present, since the course is planned as a "five-year project”.

This is supported by the fact that the interim summary and previous research studies which examined development and change of teachers' perceptions in technology-assisted teaching environments, indicated that it was possible to see assimilation of and change in perceptions through a process over time. We expect that certain measurements that were examined will show a trend of improvement through the next phases of the project. Yet, the integration of technology is not the main issue for examination, but rather the assimilation of new perceptions and contents, a new educational-pedagogic approach, and the varied consideration of a wealth of possibilities embodied in different types of technology. In these areas, already in the first two years, we saw satisfactory data indicating that the principles of the program had been implemented.

Every alteration and introduction of change is liable to encounter resistance. This was seen in the study by Forkosh-Baruch (2005) that analyzed case studies concerning the integration of new pedagogic innovations: "the introduction process for innovation can be described and exemplified through the use of the diffusion of innovation 
curve, as presented by Rogers (2003)...” (Forkosh-Baruch, 2005). According to Rogers theory of diffusion of change (Rogers, 2003), the reactions of the members of an organization that adopts innovation are divided into several sub-groups: innovators, early adopters, early majority, late majority and laggards. Innovators are the first to adopt the innovation. They are willing to risk a new and path-breaking experience that is sometimes very different from accepted pedagogy practiced in schools. Early adopters, the second category of innovating teachers, in many cases have leadership abilities and therefore assist the dissemination of innovation among school staff. The teachers who lead innovation in schools belong to these first two groups. The next group, the early majority, is also ahead of many others and is considered too as pioneers. The data presented so far hint that many of the student-teachers who took the EFTF course were ready to become pioneers in adopting innovative pedagogies not yet seen in their schools.

The issues and data discussed above prompt various questions that need broad clarification. How can the early majority of pioneers be broadened through a "new pedagogy"? Will it be possible within a period of 3 - 5 years to see a change in the innovation adoption curve among student teachers in the Ohalo Academic College? Which teaching methods should be used to improve the learning processes? Which skills are more meaningful for the educators of the future? How is it possible to overcome the variance and despite the many difficulties to succeed in establishing the innovative pedagogy in the social and geographic peripheries of Israel, forming an alternative learning? These questions constitute a fertile bed for further research, whose "last words" have yet to be uttered. These questions could point up directions for follow-up research to enlarge the discussion on the issues that emerged from the present research over time with the development of the project.

\section{Acknowledgements}

We would like to express our appreciation to the MOFET Institute for its financial support for this study.

\section{References}

Abu Ahmed, W. (2010). Internet Usage Patterns and Motivations among Students in the Alquasemi Academy. E-Book. (in Hebrew) http://ebookbrowse.com/heb-7-walid-abu-ahmed-pdf-d385597557

Center for Educational Technology (2010). Education for the 21st Century-The Growth Engine of the State of Israel. Conference Herzliya. (in Hebrew) http://storage.cet.ac.il/edu2010/edu2010.pdf

Forkosh-Baruch, A., Nachmias, R., Miodusar, D., \& Tubin, D. (2005). "Islands of Innovation” and "School-Wide Implementation”: Two Patterns of ICT-Based Pedagogical Innovations in Schools. Human Technology: Interdisciplinary Journal on Humans in ICT Environments, 1, 202-215.

Levin, T., \& Wadmany, R. (2008). Teachers Views on Factors Affecting Effective Integration of Information Technology in the Classroom. Journal of Technology and Teacher Education, 16, 233-263.

Melamed, U. (2010). Computers in the Classroom and the Teacher in the Corner. Hed Hachinuch, 85, 76-79. (in Hebrew)

Mioduser, D., Nachmias, R., Tubin, D., \& Forkosh-Baruch, A. (2006). Innovative Pedagogical Practices Using Information and Communication Technologies. Israel: Ramot. (in Hebrew)

Mishra, P., \& Koehler, M. J. (2006). Technological Pedagogical Content Knowledge: A Framework for Teacher Knowledge. Teachers College Record, 108, 1017-1054. http://online.mofet.macam.ac.il/file.php/214/mishra-koehler-tcr2006.pdf http://dx.doi.org/10.1111/j.1467-9620.2006.00684.x

Nachmias, R., et al. (2004). Factors Involved in the Implementation of Pedagogical Innovations Using Technology. Education and Information Technologies, 9, 291-308. (online) http://muse.tau.ac.il/publications/86.pdf

Oliver, R. (1994). Factors Influencing Beginning Teachers’ Uptake of Computers. Journal of Technology and Teacher Education, 2, 71-89.

Rimon, A. (2010). Meeting of the Knesset Education, Culture and Sport Committee Concerning the Subject: Adaptation of the Education System to the 21st Century. Protocol 197. (in Hebrew)

http://www.knesset.gov.il/protocols/data/html/chinuch/2010-04-26.html

Rogers, E. M. (2003). Diffusion of Innovation (5th ed.). New York: Free Press.

Sarason, S. B. (1993). The Case for Change: Rethinking the Preparation of Educators (Vol. xv). San Francisco, CA: JosseyBass.

Segal-Drori, O., Korat, O., Shamir, A., \& Klein, P. S. (2009). Reading e-Books and Printed Books with and without Adult Instruction: Effects on Emergent Reading. Reading and Writing, 23, 913-930.

http://dx.doi.org/10.1007/s11145-009-9182-x 
Sergiovanni, T. A. (2002). School Management, Theoretical and Practical Aspects. Tel-Aviv: Open University. (in Hebrew)

The Partnership for 21st Century Skills (2003). Learning for the 21st Century. Washington, DC. http://www.p21.org/storage/documents/P21_Report.pdf

The Partnership for 21st Century Skills (2010). 21st Century Knowledge and Skills in Educator Preparation. Washington, DC. http://www.p21.org/storage/documents/aacte_p21_whitepaper2010.pdf

Wadmany, R., \& Levin, T. (2004). The Use of Information Technologies in the Classrooms: Patterns of Change and Development in Educational Beliefs and in Educational Practices among Teachers and Their Students. In: R. Ferding, C. Crawford, R. Carlsen, N. Davis, J. Price, R. Weber, \& D. A. Willis (Eds.), Society for Information Technology and Teacher Education-Information Technology Diffusion/Integration (pp. 4295-4299). Norfolk, VA: AACE. 
Scientific Research Publishing (SCIRP) is one of the largest Open Access journal publishers. It is currently publishing more than 200 open access, online, peer-reviewed journals covering a wide range of academic disciplines. SCIRP serves the worldwide academic communities and contributes to the progress and application of science with its publication.

Other selected journals from SCIRP are listed as below. Submit your manuscript to us via either submit@scirp.org or Online Submission Portal.
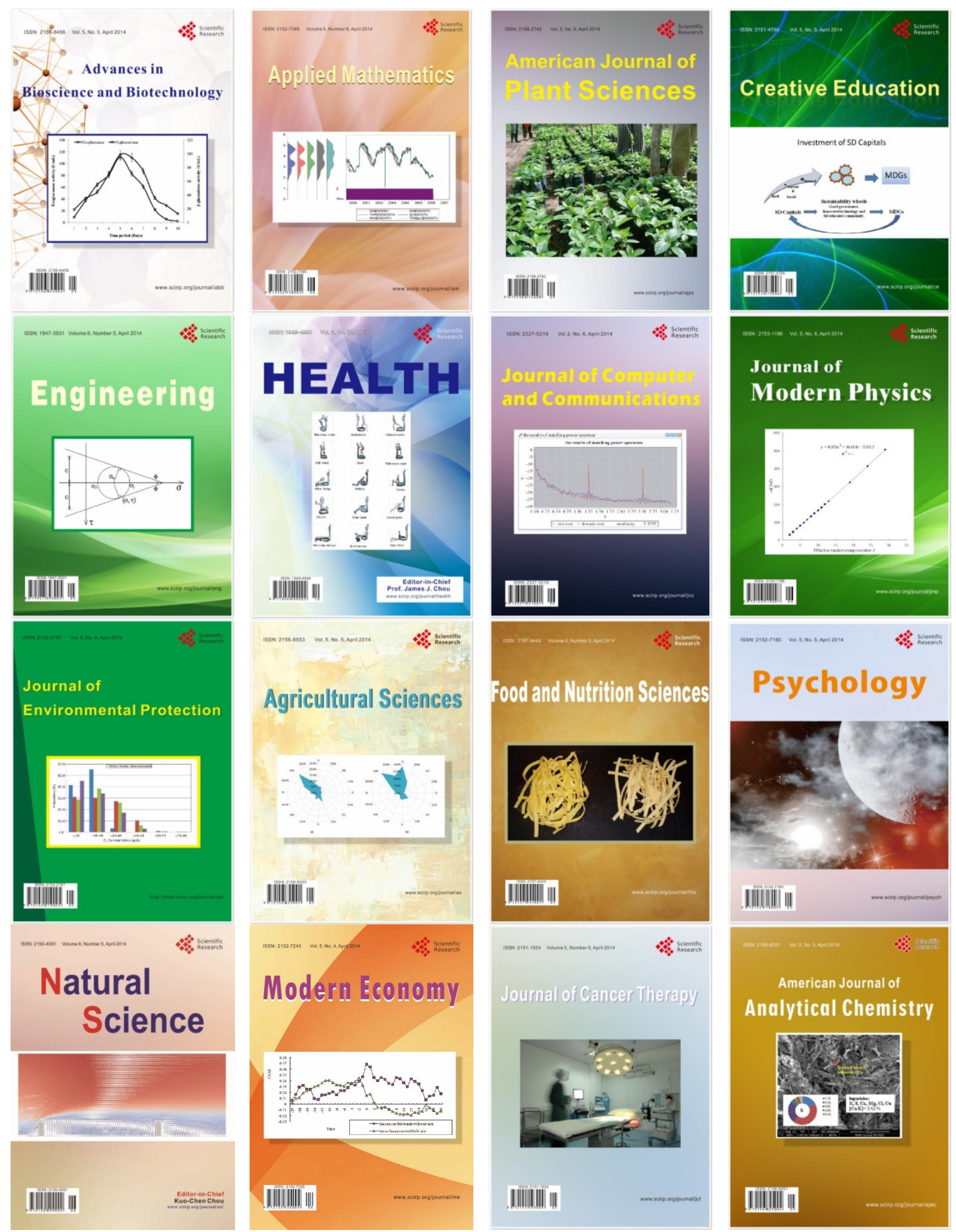